\title{
Instituto de Geociências da USP e herança cultural: estreitando os laços
}

Eliane Aparecida Del Lama*

Instituto de Geociências - USP

Departamento de Mineralogia e Geotectônica - GMG

Rua do Lago, 562 - Cidade Universitária

CEP 05508-080 - São Paulo, SP. Telefone: +(11) 3091-3994

www.igc.usp.br e-mail: gmgigc@usp.br

\section{Resumo}

O Instituto de Geociências da USP está ampliando seu campo de atuação na área de pesquisa de Mineralogia Aplicada, enfocando estudos sobre herança cultural. Como estudo de caso, este trabalho apresenta as técnicas mineralógico-analíticas usadas na caracterização de pinturas murais, em particular os afrescos de Fulvio Pennacchi na Capela do Hospital das Clínicas. O trabalho foi efetuado em projeto conjunto com o Centro de Preservação Cultural (CPC) da USP, representando, assim, uma interação de cientistas da área de ciências exatas com cientistas da área de conservação e preservação de bens culturais, interação esta cada vez mais importante para esta área de atividade.

\section{Introdução}

As contribuições que a Geologia pode fornecer para a preservação da Herança Cultural são inúmeras (DEL LAMA, 2007), tais como: identificação de pigmentos e caracterização de argamassas de pinturas artísticas; identificação das rochas usadas em construções históricas; estudo de intemperismo de monumentos rochosos; caracterização mineralógica de azulejos antigos; geoarqueologia (estudos de proveniência, composição e idade de objetos arqueológicos); pinturas rupestres; caracterização de sítios arqueológicos sob pontos de vista geomorfológico e sedimentológico, e de localização e identificação de sítios subterrâneos; além da preservação e divulgação do patrimônio natural.

A complexidade do tema referente à conservação, preservação e recuperação de patrimônio histórico ou herança cultural envolve múltiplos métodos de análise, no 
sentido da determinação dos materiais que os compõem. Estes métodos são, na sua maioria, métodos tradicionalmente utilizados em mineralogia.

O Departamento de Mineralogia e Geotectônica (GMG) do Instituto de Geociências (IGc) da USP iniciou recentemente a linha de pesquisa em preservação e recuperação de patrimônio histórico.

O primeiro passo foi a realização do projeto Fapesp n. 05/51310-3 intitulado $A$ Mineralogia aplicada ao estudo de Pinturas Murais: Fulvio Pennacchi - Um Estudo de Caso, resultando em várias publicações (DEL LAMA; TIRELLO, 2005; DEL LAMA et al, 2006; TIRELLO; DEL LAMA, no prelo; DEL LAMA et al, no prelo) e será exemplificado neste trabalho.

Tese de doutoramento (FRASCÁ, 2003) e trabalhos de formatura (STERN, 2001; REYS, 2006) já foram realizados no IGc-USP.

Em 2006, foi oferecida a disciplina de pós-graduação CONSERVAÇÃO E RESTAURAÇÃO DO PATRIMÔNIO HISTÓRICO CONSTRUÍDO, em colaboração com o geólogo José Delgado Rodrigues do Laboratório Nacional de Engenharia Civil (LNEC), de Lisboa, Portugal.

A continuidade das pesquisas envolve a implantação de rotinas nos laboratórios existentes no IGc-USP, montagem de um laboratório específico e desenvolvimento de pesquisas no estudo e preservação do patrimônio cultural, e também estreitar os contatos com centros especializados que tenham acervo e experiência no ramo, mas que contam com pouco ou nenhum suporte mineralógico.

\section{Métodos adotados}

O estudo de caso realizado refere-se a dois afrescos do pintor italiano Fulvio Pennacchi (1905-1992) na Capela do Hospital das Clínicas (Figura 1) da Faculdade de Medicina da Universidade de São Paulo (FMUSP), em São Paulo: Anunciação da Virgem (1947) e Ceia de Emaús (1947). O objetivo foi auxiliar no diagnóstico científico de conservação, e propor diretrizes para futuros trabalhos de restauração. Estas obras foram tombadas pelo Condephaat (Processo 9079/69) e pelo Conpresp 
(Processo 16-001.857-91*00) e podem ser visualizadas no livro Bens imóveis tombados ou em processo de tombamento da USP (OBRAS..., 2002, p. 60-65).

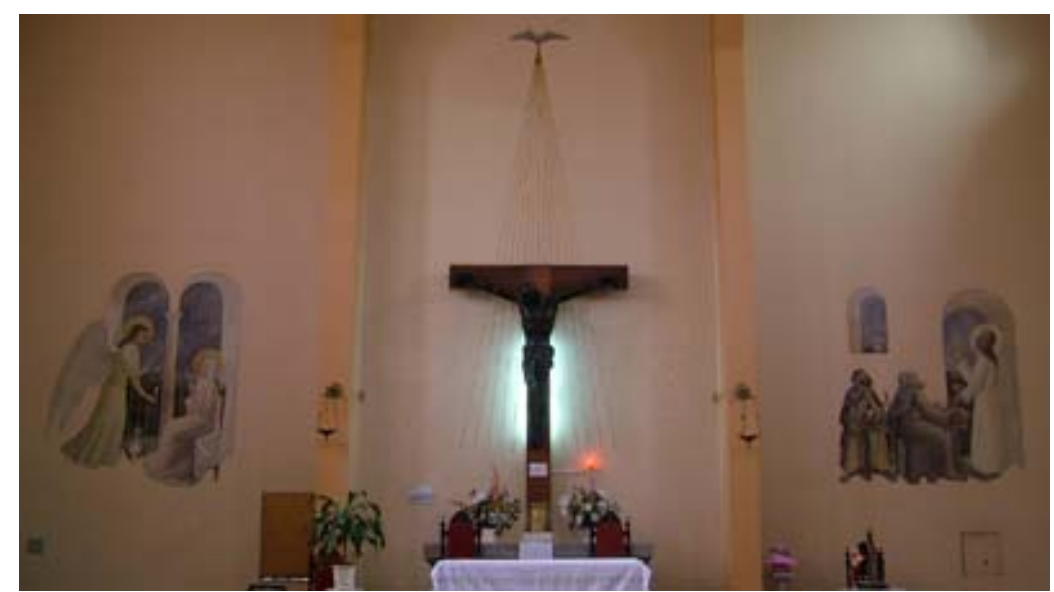

FIGURA 1 - Afrescos Anunciação da Virgem e Ceia de Emaús de Fulvio Pennacchi realizados na Capela do Hospital das Clínicas da Faculdade de Medicina da Universidade de São Paulo (FMUSP) em 1947.

Esse trabalho foi efetuado em projeto conjunto com o Centro de Preservação Cultural (CPC) da USP, que desenvolve trabalhos pioneiros em pinturas parietais desde 1988, por meio do programa "Conservação e Restauro de Bens Arquitetônicos e Integrados", coordenado pela Profa. Dra. Regina A. Tirello.

O CPC realizou estudos tecno-formais, diagnósticos do estado de conservação e a seleção dos pontos de micro-amostragem das obras da Capela do Hospital das Clínicas. Posteriormente, com a obtenção dos dados analíticos, foi feita a interpretação conjunta dos resultados.

Das duas pinturas murais, a Anunciação da Virgem $(232 \mathrm{~cm} \times 265 \mathrm{~cm})$ apresenta-se em estado razoável de conservação, apresentando apenas eflorescência na parte superior. A outra obra, Ceia de Emaús $(237 \mathrm{~cm} \times 245 \mathrm{~cm}$ ), está bastante danificada e com aspecto pulverulento, com desagregação da superfície colorizada da massa, deixando à vista o reboco subjacente e provocando perda de coesão nos constituintes da argamassa.

As técnicas analíticas de identificação aqui utilizadas foram: estereomicroscopia, microscopia eletrônica de varredura com EDS, difração de raios $\mathrm{X}$, microssonda eletrônica e obtenção de imagem por radiação ultravioleta. A utilização conjunta destas técnicas torna possível a identificação dos componentes da argamassa, suas respectivas proporções e as possíveis camadas existentes, além de informações a 
respeito da granulação, impurezas minerais presentes e características texturais dos minerais; e a identificação dos pigmentos utilizados pelo pintor; além da caracterização de feições de deterioração e estudo de cristalização dos sais.

Todas as análises foram realizadas em laboratórios específicos do Instituto de Geociências da USP.

As amostras coletadas foram analisadas em Estereomicroscópio da Zeiss, modelo STEMi SV8 (Figura 2), e fotografadas com câmera digital.

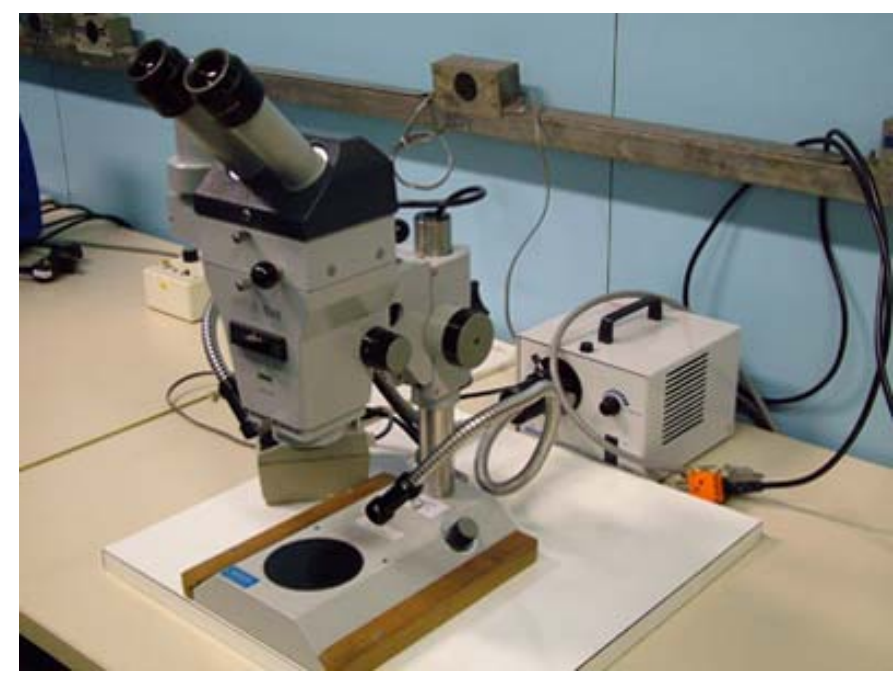

FIGURA 2 - Estereomicroscópio da Zeiss, modelo STEMi SV8 do Instituto de Geociências da USP.

A difração de raios X (Figura 3) foi utilizada, principalmente, para a identificação dos sais das eflorescências nos murais, e auxiliou na identificação de minerais da argamassa.

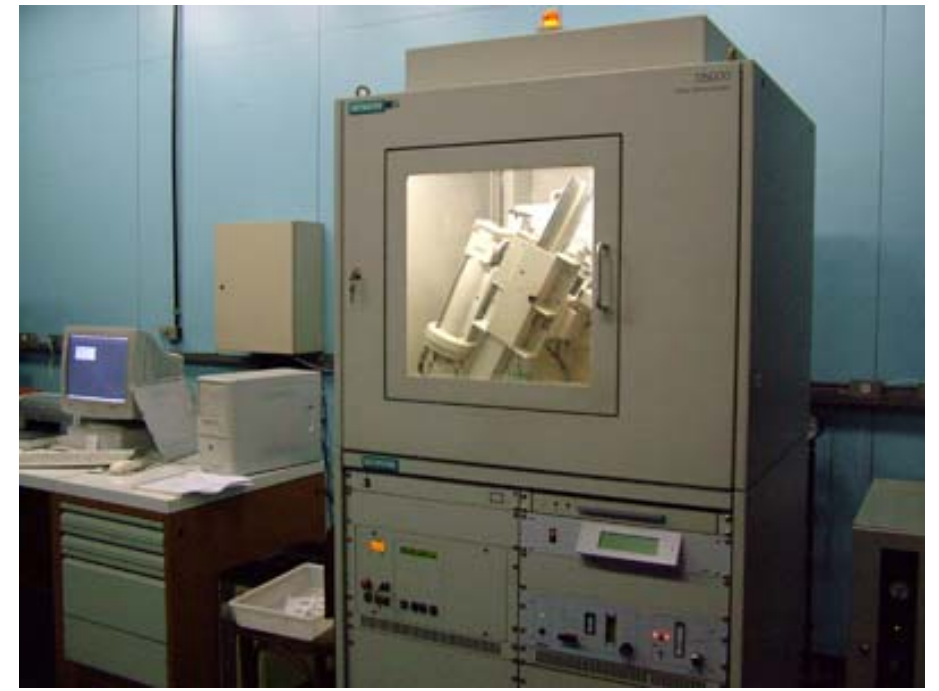

FIGURA 3 - Difratômetro de raios $X$ Siemens, modelo D5000, do Instituto de Geociências da USP. 
A caracterização dos materiais é auxiliada pela microscopia eletrônica de varredura com EDS (espectroscopia de energia dispersiva de raios X) acoplado (Figura 4), que fornece análises químicas pontuais e a obtenção de imagens de grandes aumentos. O microscópio eletrônico de varredura (MEV) foi utilizado para a identificação de camadas e suas espessuras, composição e compacidade da argamassa, e identificação da composição dos pigmentos.

A microssonda eletrônica (ME - FIGURA 5) foi utilizada para complementar as análises do MEV.

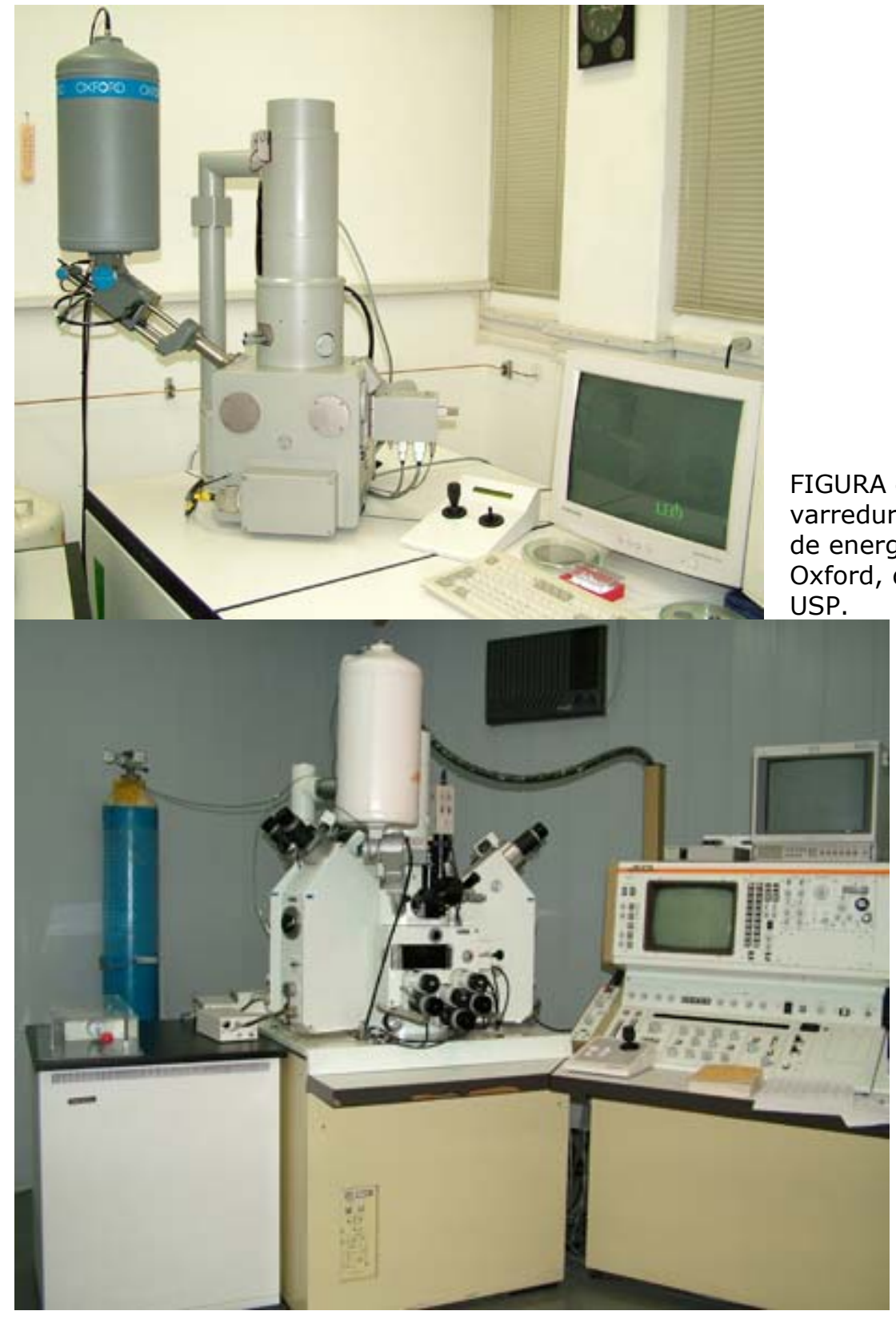

FIGURA 5 - Microssonda eletrônica, JXA-8600 SuperProbe (JEOL), do Instituto de Geociências da USP. 
A obtenção de imagens sob radiação ultravioleta auxilia na identificação dos pontos da obra mais apropriados para a retirada de micro-amostras nas pinturas murais, já que indica as eventuais anomalias e/ou características executivas não observáveis a olho nu.

\section{Resultados}

Os resultados obtidos são aqui apresentados muito sucintamente e exemplifica as respostas que podem ser obtidas com as técnicas analíticas utilizadas.

A difração de raios $X$ permitiu a identificação da composição química da argamassa e das eflorescências salinas. A Figura 6 mostra um difratograma identificando os minerais gipsita e epsomita presentes nas eflorescências salinas, ratificado pelas análises de MEV (Figura 7).

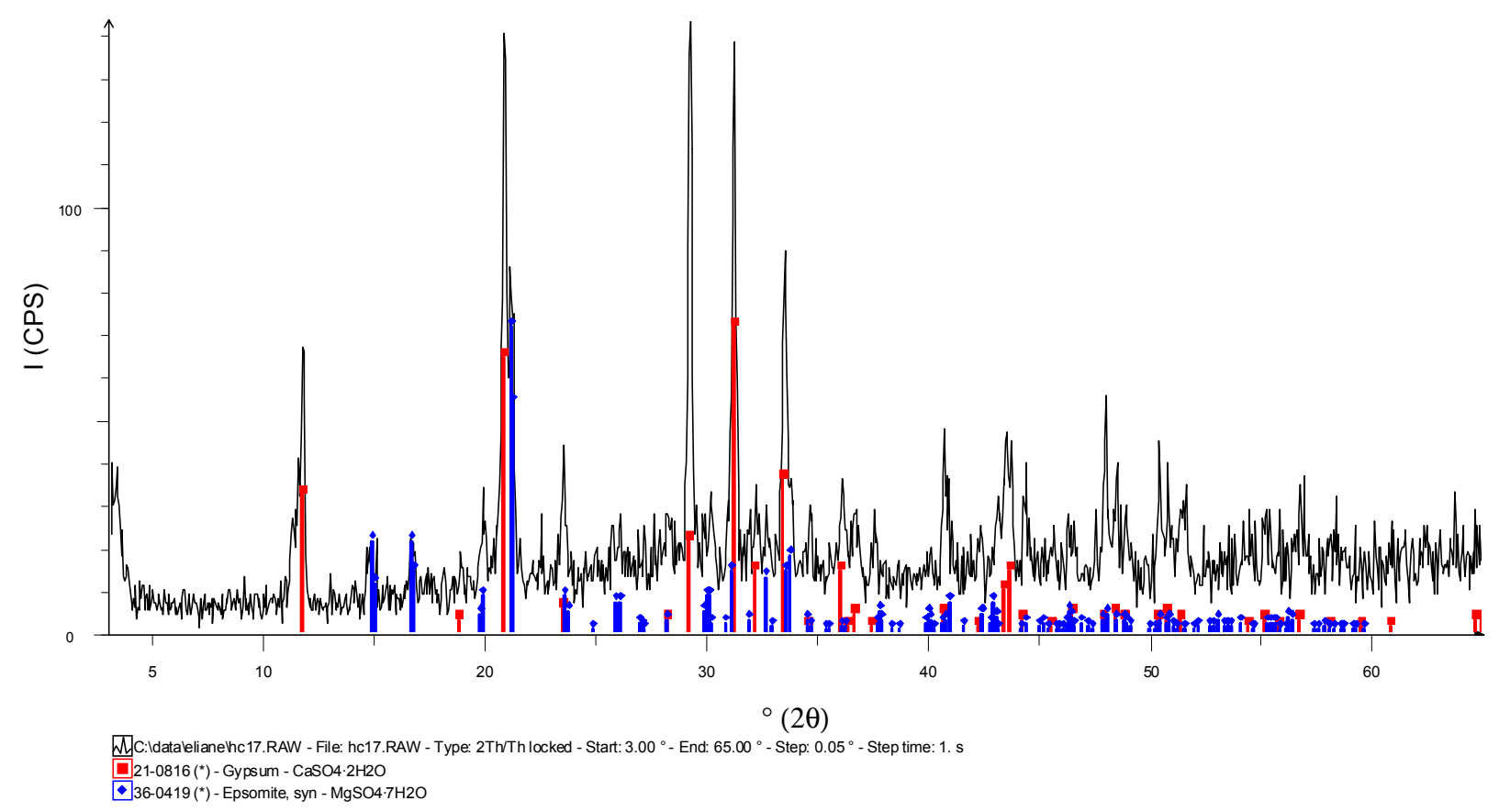

FIGURA 6 - Difratograma de raios X indicando a presença de gipsita e epsomita em eflorescências salinas. Difratograma: Flávio M. S. Carvalho. 

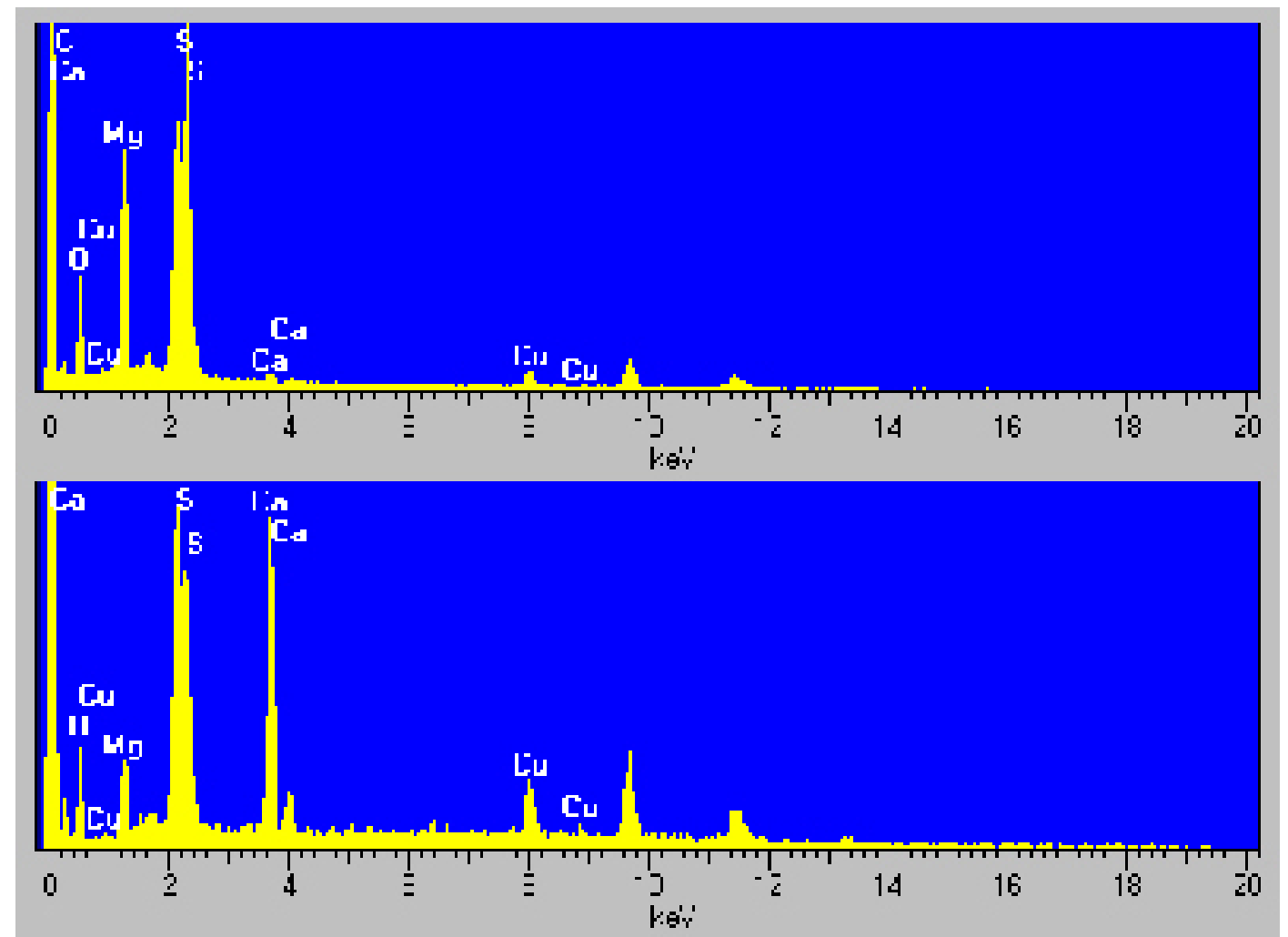

FIGURA 7 - EDSs de eflorescências salinas apontando a presença de sulfato de magnésio e sulfato de cálcio. EDS: Isaac J. Sayeg.

As informações químicas, associadas às observações ao estereomicroscópio e ao $\mathrm{MEV}$, confirmadas por difratogramas de raios $\mathrm{X}$, permitiram identificar os seguintes minerais na argamassa: quartzo, muscovita, biotita (muito localmente), microclínio, calcita, caulinita, ilmenita, monazita, zircão.

A partir das imagens obtidas no MEV foi possível o mapeamento de dois grandes grupos de texturas observadas nos afrescos: argamassa com aspecto granuloso (textura tipo 1 - Figura 8) e argamassa com aspecto mais liso, podendo formar uma fina camada (textura tipo 2 - Figura 9).

Outra informação que pode ser fornecida pelo MEV é a presença de microorganismos (Figura 10). 


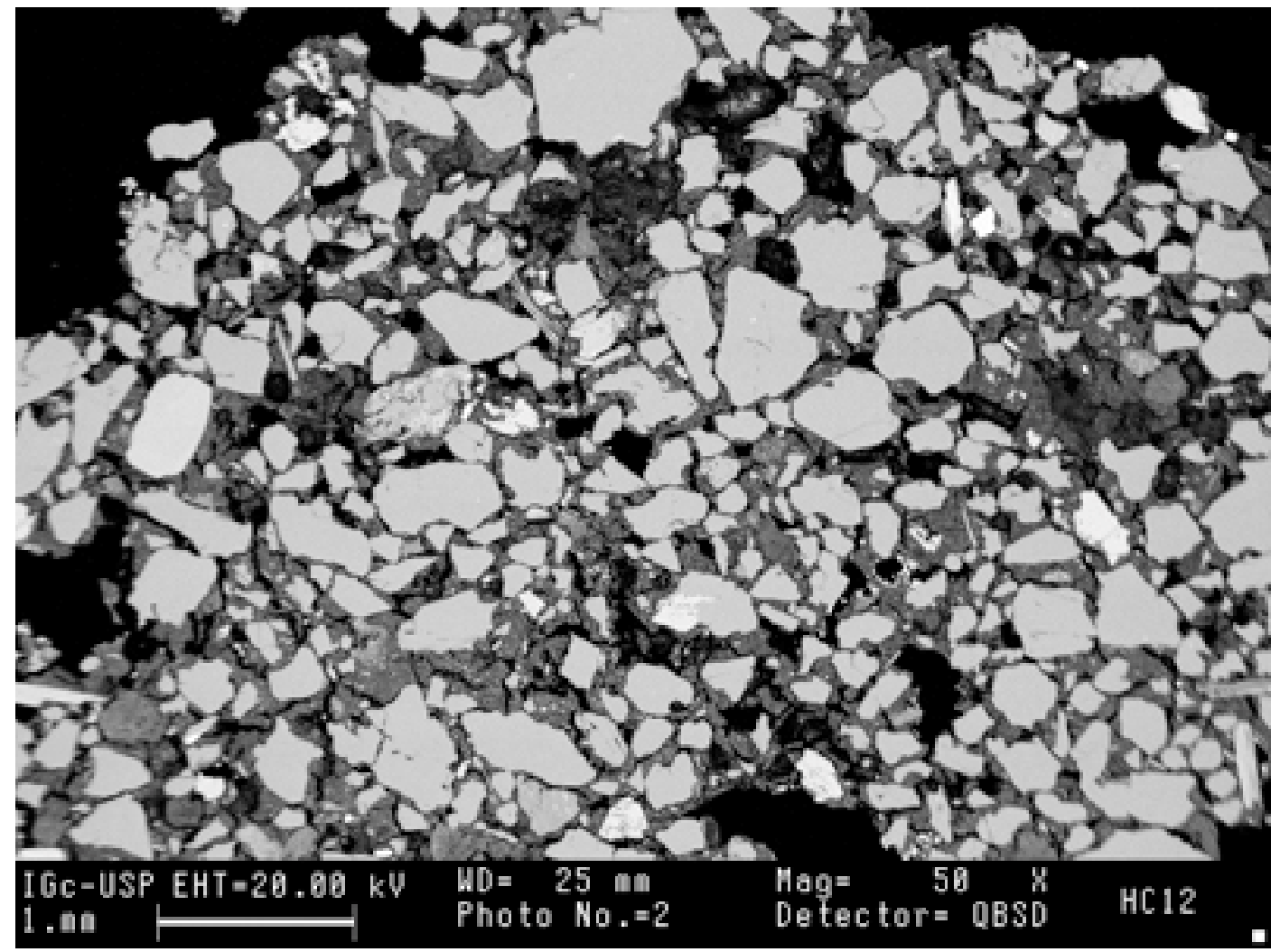

FIGURA 8 - Imagem de microscopia eletrônica de varredura apresentando textura tipo 1: argamassa com aspecto granuloso. Imagem: Isaac J. Sayeg.

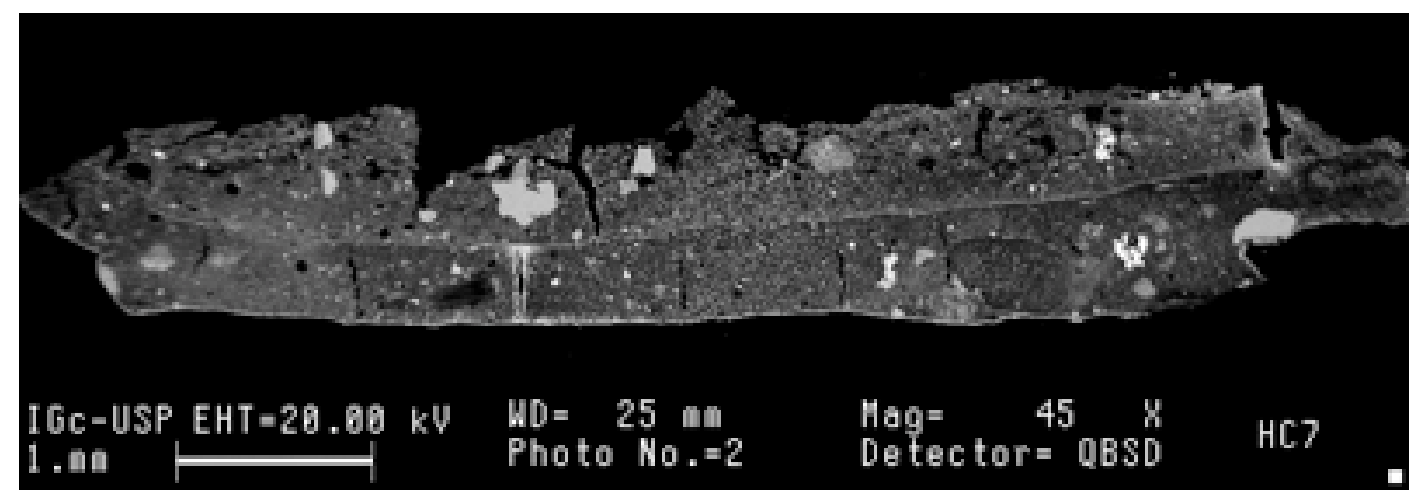

FIGURA 9 - Imagem de microscopia eletrônica de varredura apresentando textura tipo 2: argamassa com aspecto mais liso, podendo formar uma fina camada. Imagem: Isaac J. Sayeg. 


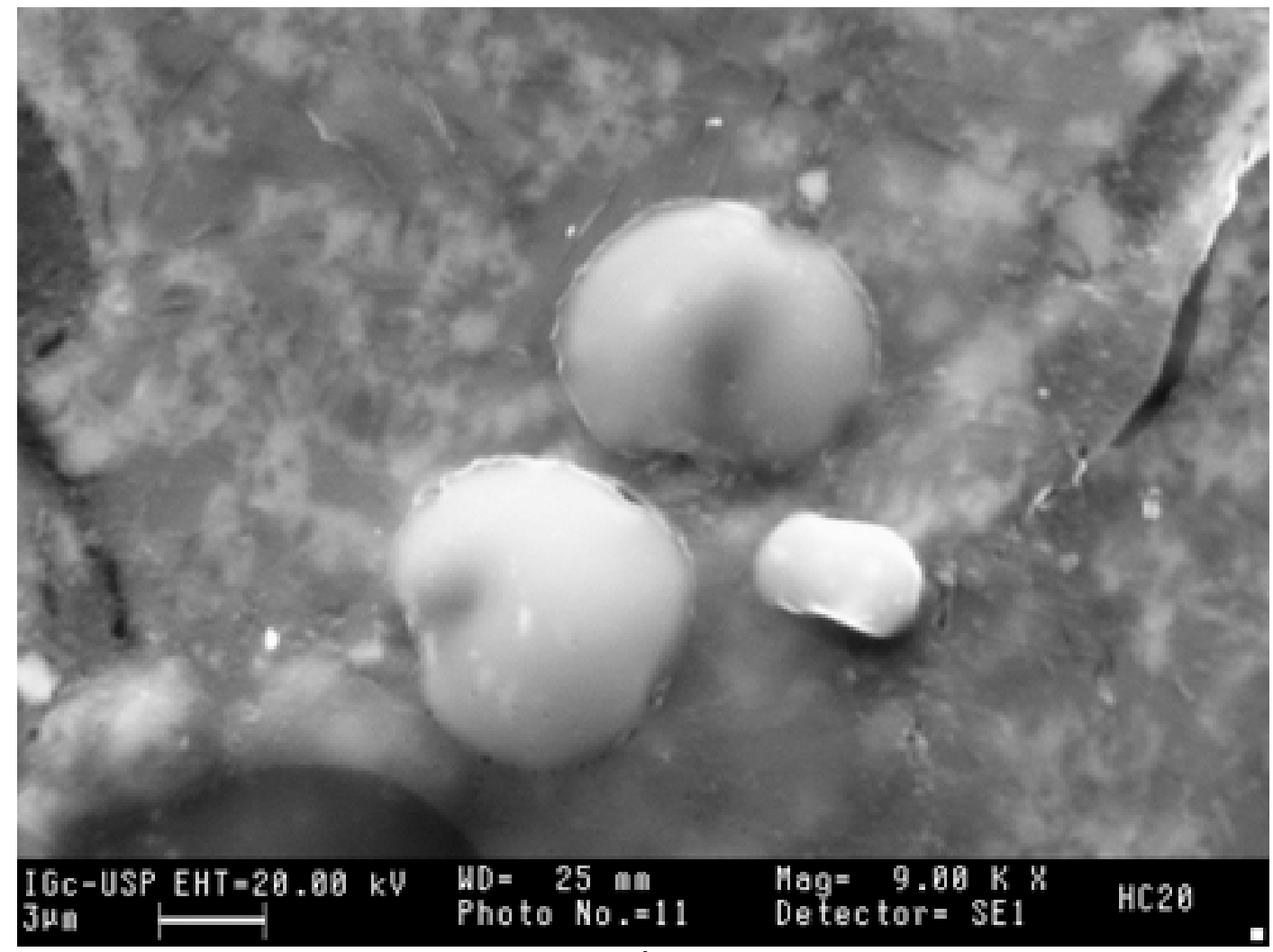

FIGURA 10 - Imagem de microscopia eletrônica de varredura apresentando estruturas semelhantes a esporos fúngicos com características deformadas devido ao alto vácuo. Imagem: Isaac J. Sayeg.

\section{Considerações finais}

Os estudos aqui realizados tiveram caráter multidisciplinar e envolveram pesquisadores do Instituto de Geociências (IGc) e do Centro de Preservação Cultural (CPC) da Universidade de São Paulo (USP). Os resultados obtidos constituem informações que subsidiam o diagnóstico científico do estado atual de conservação destas obras, e como desdobramento de futuras pesquisas, auxiliar nos trabalhos de restauração.

Espera-se que ocorra uma maior inserção do geólogo na temática, permitindo sua participação em equipes multidisciplinares que atuem em preservação e restauração da herança cultural, ampliando assim o campo de atuação e a contribuição do geólogo no âmbito socio-cultural.

\section{Referências bibliográficas}

DEL LAMA, Eliane Aparecida. Geologia e herança cultural. Revista Brasileira de Geociências, v. 36, n. 2, p. 379381, 2007. 
DEL LAMA, Eliane Aparecida; ANDRADE, Fábio Ramos Dias de; KIHARA, Yushiro; TIRELLO, Regina Andrade. Estudo de eflorescências em pinturas murais de Fulvio Pennacchi. ARC - Revista Brasileira Arqueometria Restauração Conservação. No prelo.

DEL LAMA, Eliane Aparecida; SHIRAKAWA, Márcia Aiko; GAYLARDE, Christine Claire; TIRELLO, Regina Andrade. Deterioração de patrimônio histórico - afresco de Fulvio Pennacchi. In: CONGRESSO BRASILEIRO DE GEOLOGIA, 43., 2006, Aracaju. Anais... Aracaju: SBG, 2006. p. 71.

DEL LAMA, Eliane Aparecida; TIRELLO, Regina Andrade. Técnicas mineralógico-texturais para a caracterização de pinturas murais. In: SIMPÓSIO DE GEOLOGIA DO SUDESTE, 9., SIMPÓSIO DE GEOLOGIA DE MINAS GERAIS, 13., 2005, Niterói. Boletim de Resumos... Niterói: SBG, 2005. p. 140.

FRASCÁ, Maria Heloísa Barros de Oliveira. Estudos experimentais de alteração acelerada em rochas graníticas para revestimento. Tese (Doutorado) - Instituto de Geociências, Universidade de São Paulo, São Paulo, 2003.

OBRAS de arte da Capela do Hospital das Clínicas. Bens imóveis tombados ou em processo de tombamento da USP. Organização Maria Cecília França Lourenço. 2. ed. São Paulo: Edusp; Imprensa Oficial do Estado de São Paulo, 2002. p. 60-65. (Cadernos CPC, 2)

REYS, Aranda Calió dos. Estado de conservação dos monumentos da cidade de São Paulo. Trabalho de Conclusão de Curso - Instituto de Geociências, Universidade de São Paulo, São Paulo, 2006.

STERN, André Gianotti. Roteiro geológico pelos monumentos e edifícios históricos da cidade de São Paulo. Trabalho de Conclusão de Curso - Instituto de Geociências, Universidade de São Paulo, São Paulo, 2001.

TIRELLO, Regina Andrade; DEL LAMA, Eliane Aparecida. La pintura al fresco moderna brasileña: estudios de caracterización material y ejecución de los murales de Fulvio Pennacchi (São Paulo/Brasil). In: CONGRESO ARGENTINO DE ARQUEOMETRÍA, 1., 2005, Rosario, Argentina. Anais... No prelo.

\section{Crédito}

* Geóloga. Doutora pelo IGCE-UNESP. Professora do IGc-USP.

e-mail: edellama@usp.br 